\title{
迈向人类健康和文明的新境界: 星球健康
}

\author{
梁松 ${ }^{(1)(3)}$
}

(1) Department of Environmental and Global Health, College of Public Health and Health Professions, University of Florida, Gainesville, FL 32610, USA;

(2) Emerging Pathogens Institute, University of Florida, Gainesville, FL 32610, USA;

(3) Florida Climate Institute, Gainesville, FL 32610, USA

E-mail: songliang@ufl.edu

美国自然基金委地学部科学基金(1360330)资助

2015 年 7 月 16 日, Lancet 杂志发表了由洛克菲勒基金 会(Rockefeller Foundation)和该杂志共同委托全球 19 家高 校、研究所和基金会, 22 位公共健康、环境科学、生态学、 公共管理及政策等领域的权威研究人员共同撰写的 "Safeguarding human health in the Anthropocene epoch: Report of The Rockefeller Foundation-Lancet Commission on planetary health" (人类世保护人类健康：洛克菲勒基金 会-柳叶刀星球健康委员会特邀报告 $)^{[1]}$. 在这份具有里程 碑意义的报告中, 一个新名词, 即星球健康 (Planetary Health) 被正式提出 ${ }^{[1]}$, 它标志着一个新领域的诞生. 星球 健康指的是通过人与自然系统的和谐发展, 人类在世界范 围内能达到最高水平的健康, 幸福和平等. 换句话说, 人 类和这一自然系统的关系决定着我们的未来.

这份长达 56 页的报告有 4 个核心要点. 第一, 星球健 康的基本理念是人类健康和文明, 取决于一个繁荣的地球 自然系统以及我们对它的明智管理. 然而, 这一自然系统 正发生着人类历史上前所未有的退化. 第二, 退化的环境 对人类健康和文明的威胁将是令人吃惊的. 尽管存在不确 定性, 我们的社会仍面临明确而又巨大的危机, 迫切需要 采取变革性的措施和行动, 来保护我们的现在和未来. 第 三, 目前的管理体系和知识水平还不足以来应对星球健康 面对的威胁. 我们呼吁建立完善的管理与协调机制, 整合 社会、经济和环境政策, 促进跨学科的新知识产生和应用, 以推进星球健康的发展. 第四, 解决方法是可及的, 但需 要我们重新认识什么是繁荣, 更多关注人类的生活质量和 健康, 以及与自然系统的和谐共处 ${ }^{[1]}$.

我们为什么需要这样一个新概念和领域呢? 人类对人 和环境关系(如生存, 发展和健康)的认识有着很长历史. 早 在公元前 400 多年前, 我们的先哲希波克拉底在他至今仍广 为流传的一本著作“Airs, Waters and Places”(空气、水和地 方)中就诠释了人的健康需要考虑他周围的环境以及人与环 境间的平衡 ${ }^{[2]}$. 大气、土地、江河、海洋、森林、湿地等, 是 人类赖以生存的生态环境, 提供了人类社会发展、文明及进 步的基础. 过去一百多年人类享受着这样的发展和进步一 农业发展满足不断增长人口的食品和营养需求; 工业、科学

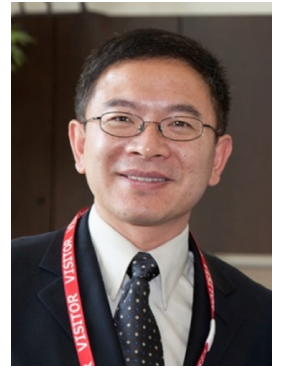

梁松美国加州大学伯克利分 校环境健康博士。现佛罗里达大学环 境及全球健康系副教授, 佛罗里达大 学新发传染性病原体研究所、佛罗里 达气候研究所研究员。在过去 10 年得 到美国国家健康研究所 (NIH), 自然 基金委(NSF)，环境保护总署(EPA)和 农业部(USDA)的资助从事环境介导 传染性疾病环境流行病学、风险暴露评价、环境变化及其 健康影响方面的研究工作。

技术进步给人类带来了现代生活方式; 公共健康体系和社 会公共设施的完善, 不断降低生活在贫穷线以下的人口比 例, 以及大幅度提高了人均期望寿命一全球健康水平取得 了极大的进步. 然而, 伴随着这样的发展是人类对环境的过 度开发利用以及生态环境在全球范围的改变, 导致了前所 未有的环境后果, 诸如过度的森林砍伐和渔业捕捞、生物多 样性的降低、湿地面积的减少、空气和水的污染、温室气体 的排放和气候的变化等 ${ }^{[3]}$. 人类和环境间的平衡关系被打 破, 对全球健康来之不易的成果造成了严峻的挑战. 2006 年 世界卫生组织的报告估计目前至少有 $25 \%$ 的人类疾病负担 归因于可改变的环境因素 ${ }^{[4]}$. 人类的进步和发展又因为我 们导致的环境退化受到损害, 变得不可持续.

星球健康把人类健康放置于人和自然系统中. 一方面, 我们面临的诸多健康风险来自于可改变的环境本身, 而这 些环境因素很大程度上是由我们人类自身导致的. 同时, 这一概念也关注我们赖以生存的自然系统和系统里的生 物物种, 它们的相互作用和这一系统的健康. 传统公共健 康(Public Health)的重要理念之一是隔离(Seperation), 为保 护健康把我们和周围的“危险”环境隔离开来. 譬如, 通过 建立卫生则所和饮用水设施，把我们和经粪口传播的病原 体分开, 利用疫苗防止很多传染性病原体的人侵, 利用个 人防护减少对空气污染的暴露等. 这一理念和相应的措施 在过去一个世纪取得了举世瞩目的成效, 也将继续发挥它 
的作用. 但在全球环境发生前所未有剧烈变化的今天, 传 统的公共健康理念亟需拓展, 需要把人类健康、环境健康 和支撑这种健康的系统, 如自然生态系统的功能和社会经 济的发展, 有机结合起来, 才能维护我们人类健康和文明 的可持续性发展 ${ }^{[1]}$.

针对面临的核心问题，星球健康报告提出了一系列应 对的策略及行动计划框架. 譬如, 温室气体减排, 满足日 益对食物、营养增长的需求和环境承载能力间的平衡, 发 展可持续的农渔业, 提倡对环境影响小的健康饮食方式, 建立可持续发展的城市环境等 ${ }^{[1]}$. 但我们如何建立一个可 操作的星球健康框架, 并实施以达到我们所期望的目标, 仍面临相当多的挑战. 正如报告中所总结的: 第一, 要克 服观念上的误区, 我们过度依赖国内生产总值(GDP)作为 人类社会进步的指标, 忽略考虑目前的发展模式对未来人
类健康和环境的损害, 以及这些损害对发展中国家的不均 衡影响. 第二, 知识的鸿沟, 我们缺乏对影响健康的社会 和环境驱动因素的系统认识, 导致决策部门在处理环境及 健康问题中缺乏应对不确定性的能力. 跨学科研究及相应 资助的不足是其中的主要原因之一. 第三，管理和实施上 的不足, 譬如政府和相关机构在环境危机出现时认识和反 应的延滞(尤其是在面对各种不确定性时).

挑战与机遇并存. 星球健康的提出建立了一个新的领 域和认识平台, 同时也提供了前所未有的机遇一与联合 国可持续性发展目标和 2015 后发展议程相呼应一一通过 新知识和技术的应用及改善的管理，将公共健康和可持续 性发展结合起来. 为了人类的健康和未来, 我们亟需跨学 科、跨部门、跨地域的专业人员、公民及决策者间的紧密 合作, 采取切实行动改善我们人类赖以生存星球的健康.

\section{推荐阅读文献}

1 Whitmee S, Haines A, Beyrer C, et al. Safeguarding human health in the Anthropocene epoch: Report of The Rockefeller FoundationLancet Commission on planetary health. Lancet, 2015, doi: http://dx.doi.org/10.1016/S0140-6736(15)60901-1

2 Rosen G. A History of Public Health (Expanded edn). Baltimore: Johns Hopkins University Press, 1993

3 Corvalán C, Hales S, McMichael A J. Millennium Ecosystem Assessment (Program). In: World Health Organization, ed. Ecosystems and Human Well-being: Health Synthesis. Geneva: World Health Organization, 2005

4 Pruss-Ustun A, Corvalan C. Preventing Disease Through Healthy Environments: Towards an Estimate of the Environmental Burden of Disease. Geneva: World Health Organization. 2006 